\title{
Individual Driving Behaviour in Wildfire Smoke
}

\author{
Niklas Wetterberg, Enrico Ronchi (D) and Jonathan Wahlqvist, Department of \\ Fire Safety Engineering, Lund University, Lund, Sweden
}

Received: 26 March 2020/Accepted: 21 July 2020

\begin{abstract}
This work presents the results of a virtual reality (VR) experiment aiming at investigating how individual driving behaviour is affected by the presence of wildfire smoke. The experiment included a driving simulation task to study the chosen driving speed at different smoke densities and the lateral position of the driven car on the road cross section. During the VR experiment, participants were presented with a simulated wildfire evacuation scenario including the presence of smoke through a head mounted display and were given a task to evacuate via car using a steering wheel and pedals on a single carriageway road with two lanes. A total of 46 participants took part in the experiments and their driven trajectories along with their instantaneous speed were collected in 5 different visibility conditions. Driving speed decreased with increasing smoke density. No difference in choice of speed was found in relation to the smoke density in the previously driven road segment (in thicker or thinner smoke). No difference in lateral position (closer to or further from the centreline of the road) at different smoke densities was found. Suggested correlations between driving speed and wildfire smoke density are provided in this paper, referring to either a fractional reduction of the speed in smoke-free conditions or an absolute choice of speed at a given visibility condition. These correlations are useful to provide more accurate estimation of evacuation times with traffic evacuation modelling tools in case of wildfire and wildland-urban interface fire scenarios.
\end{abstract}

Keywords: Driving speed, Driving behaviour, Wildfire, Smoke density, Traffic modelling, Traffic evacuation

\section{Introduction}

Private cars are the main mode of transportation during evacuations caused by wildfires [36]. The area affected by a wildfire is highly dependent on weather changes and topography, making it difficult to predict who needs to evacuate and when [24]. In addition, wildfires can create updrafts which can launch burning materials, called firebrands, into the atmosphere, causing the so called spotting phenomenon [2, 41]. This can lead to the development of fire-fronts kilometres away from the current location. This poses a set of challenges from the evacuation perspective, among which the possibility for people to be located in an area where smoke is present. Smoke emission can have a direct impact on human behaviour

\footnotetext{
* Correspondence should be addressed to: Enrico Ronchi, E-mail: enrico.ronchi@brand.lth.se
} 
during a wildfire scenario by potentially triggering the evacuation process, affect the choice of evacuation route, and affect the choice of speed while driving away from the danger $[15,23]$.

While human response in case of wildfire scenarios has been investigated in several studies $[5,11,26]$, to date, there is little to no knowledge on how people drive on roads where wildfire smoke is present [32]. This is a key issue during large scale evacuations, as reduced speeds may affect evacuation times, thus putting the evacuating population in higher danger [36]. This scenario has been reported in several actual wildfire evacuation scenarios (e.g. the 2016 Fort McMurray fire in which smoke hindered the evacuation process [43]).

In the context of building evacuation, studies have found that people often choose to move through smoke while on foot [35]. Several experimental studies $[12,18,31]$ showed that people walking through smoke tend to decrease their movement speed with increased smoke density. This behaviour is linked to the fact that people have a shorter range of visible space and are afraid to be confronted with an unseen obstacle [31]. As for the case of walking speed in building evacuation, it is also important to understand if the reduction in driving speed is linked to the speed in clear conditions [33].

During an evacuation scenario, the conditions faced may cause drivers to attempt increase their driving velocity due to the urgency of the situation [28]. Currently, the main bulk of research conducted on driving behaviour in reduced visibility conditions relate to driving in fog (i.e. a non-emergency situation). In low-visibility conditions, drivers might rely on their own speed estimation rather than the speedometer in order to keep their attention on the road [8]. For instance, in presence of fog, the perceived speed may be lower than the actual speed, thus drivers might adopt a speed faster than their target speed $[39,45]$. The chosen driving speed in fog can also be affected by the degree of experience of the driver [27]. A research study reports that drivers reduce their speed in low-visibility conditions by approximately $40 \%$ in order to increase safety [45].

In order to perform an accurate assessment of driving behaviour on the road, a set of key issues have been identified, namely (1) to build a correlation between driver speeds and smoke density and (2) to assess the extent to which the driving speed is affected by the speed adopted in the previous road segment having different visibility conditions (better or worse), (3) to check if the lateral position of the vehicle on the road is affected by presence of smoke, and 4) to study if the driving speed through smoke can be linked to the driving speed in clear conditions.

To address these issues, a virtual reality (VR) experiment with a head mounted displays (HMD), steering wheel and pedals has been conducted. The use of a steering wheel and pedals is common in driving simulators and HMDs are more and more used in fire evacuation research [19]. 


\section{The Experiments on Driving Behaviour Through Smoke}

Different methodological approaches exist to collect data on driving behaviour in emergency evacuation scenarios. Data from driving behaviour during actual wildfire evacuation accidents have the highest validity. Nevertheless, the occurrence of a wildfire scenario cannot be precisely predicted, data are difficult to obtain and are generally not publicly available. In addition, the information available on reported smoke density during wildfires at the driver height is limited and is generally associated with a low accuracy. Given the need to study driving behaviour at controlled varying smoke density level, the use of a laboratory experiment has been chosen. Due to ethical, practical and financial constraints, the use of driving simulators displaying a VR environment has been identified as an ideal tool to perform this study. Those tools have been proved to be able to elicit different driving behaviour in relation to emotions [16]. A comparison of different types of research methods for fire evacuation research [19] highlights that VR experiments require a low time and cost for data collection, they allow the possibility of exact replication and full experimental control. A key issue to address in VR experiments is the lack of costs in terms of physical harm, monetary losses and/or liability of actions [3]. This might correspond to the lack of monetary or health consequences associated with damaging the car or having an accident in the present experiments. It is therefore crucial to design the VR scenarios and provide instructions which will elicit realistic behaviour [37]. Compared to actual driving tests, VR is therefore a low-cost solution which allows high experimental control and it permits to continuously log the driving behaviour of participants (both in terms of their chosen speed and their trajectories by outputting the parametric equations of each participant trajectory). A within-subject experimental approach was used as this allows linking the driving behaviour in clear conditions and those in presence of smoke for each participant. This experimental approach was chosen as it was recommended in a study investigating walking speeds in smoke [31].

\subsection{Participants}

Data from a set of 46 participants were obtained (30 male, 15 female, one preferred not to say). All the participants were young university students. The ages ranged between 19 and 31 years old (an average of 21.5 and a standard deviation of 2.3 years). Participants were recruited through flyers and on-campus advertisement. Inclusion criteria were to be $18+$ and have a driving license, exclusion criteria included epilepsy, cognitive or physical impairments. An ethical assessment was conducted to evaluate if the experiment did not include any additional risks than any other driving game. The Division of Fire Safety Engineering at Lund University has received approval from the Swedish ethical board to be allowed to run VR evacuation experiments under a given set of experimental conditions and population (e.g., able-bodied participants over the age of 18).

A set of background questions were administered to assess the sample. Only five of the participants had experienced a wildfire before. One participant had been driving past a wildfire, one had smelling the smoke from a wildfire, one had been riding on the back of a friend's motorcycle, seen firefighting planes and 
smoke ahead and been instructed by a police to turn around and take a different route to their destination, one had been driving through smoke, and the final one had wildfires just outside his household. Drivers were on average quite inexperienced, with the most frequent number of years having a driving license being between 2 and 3 years and reporting driving less than $50 \mathrm{~km}$ per week. Among the participants' familiarity with the car transmission, 6 were more familiar with automatic, 27 with manual and 13 reported to be equally familiar with automatic and manual transmission. To assess their familiarity with a driving simulation task, the participants were also asked how frequently they were playing videogames. The participants were spread quite evenly among those that play videogames daily and those who rarely play videogames.

\subsection{Equipment and Software}

Different types of VR technologies are today available that can be used to perform VR experiments of evacuation scenarios, including virtual cars, driving simulators using powerwalls/multi-projector systems or head mounted displays (HMD) where driving can be arranged with different types of controllers [9, 34]. Given the lower hardware cost, easier installation and expected level of immersion, the use of an HMD connected to a steering wheel and pedals (accelerator and brake) was eventually chosen to perform this experiment. The experiments have been conducted with an HTC Vive (dual AMOLED 3.6" diagonal screen, $1080 \times 1200$ pixels per eye, $90 \mathrm{~Hz}$ refresh rate and 110 degrees field of view). A high-end gaming computer was used to meet the performance requirements of the HMD. The specifications of the computer included an Intel i7 $7700 \mathrm{k}$ CPU, Nvidia GeForce GTX 10808 GB GPU and 32 GB of RAM. The computer was capable of keeping the $90 \mathrm{~Hz}$ refresh rate throughout the experiment. This was made to ensure consistency between the rendered images during the driving task of the participants.

A steering wheel and pedals were used to steer the simulated car. The steering wheel and pedals were the Logitech ${ }^{\mathrm{TM}}$ G920 Driving Force which is commercially sold as videogame equipment. This steering wheel has force feedback, it allows reproducing shaking and it has a wheel of dimensions equal to $270 \mathrm{~mm}$ (height) $\times$ $260 \mathrm{~mm}$ (width) $\times 278 \mathrm{~mm}$ (depth). The driving task reproduced in the experiments was developed to represent a car with automatic transmission. The steering wheel was mounted on a desk and the pedals were placed on the floor below and were fixed to the floor. Participants were sitting on an ordinary chair while performing the driving task (see Fig. 1). This means that the driving positioning was slightly different than in an ordinary car.

In order to develop the VR environment in which the experiments were conducted, the game engine Unity $3 D$, commonly referred to as Unity (version 2019.2.0f1), was used. The 3D modelling software Blender (version 2.80) was used to develop the road and the ground next to the road and the geometry was then imported into Unity. This is a common workflow in the game development industry [4]. Using this game engine, it was possible to create a driving simulation which was then displayed with the HMD. This allowed the test persons to see the created environment from the perspective of a driver in a car. 


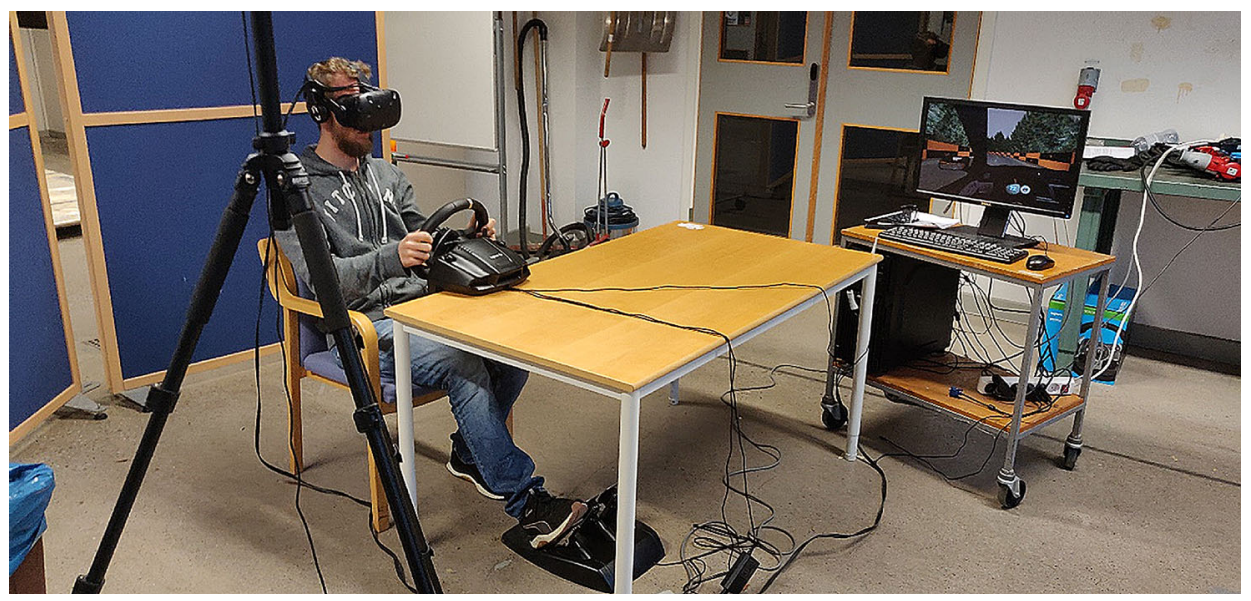

Figure 1. The experimental sefup in use during the experiments.

\subsection{The Virtual Environment}

During the experiment, each participant was driving the only car on the road. The road was deemed to reproduce a Swedish rural road with a single carriageway with two lanes, one in each direction. The road was constructed to be on a plane in order to prevent height differences to influence the driving speed. Guideposts were placed along the road and road signs were placed both to provide information to the participants about the current speed limit and to model a more realistic environment. The road signs used were limited to signs showing the speed limit $(70 \mathrm{~km} / \mathrm{h})$ and signs giving the distance to a fictitious location. No road signs in form of warning signs were used, even though they might be present in real scenarios, as this was expected to possibly be a confounding factor and affect the driving behaviours for other reasons than smoke on the road. No intersections were present on the road (in order to not elicit speed reduction due to them). The road was also created without any sharp turns in which the participant had to significantly slow down to stay on the road. The choice of this simple setup is driven by the need to remove the variables which might impact driving speed other than the presence of smoke. Being this a first study of this kind, it was deemed appropriate to focus on individual choice of speed in presence of smoke, similarly to what is currently done in research concerning walking movement in smoke [12].

The surrounding terrain was constructed to have a slope down towards the road. The slope was chosen to be high enough to make it impossible for a driver to see over the edge of the terrain, thus reducing the objects to be added in the VR environment (and subsequently improving computational performance). To further make the environment realistic and to make the case of having to perform a wildfire evacuation, trees were placed on the terrain along the road (see Fig. 2). Nevertheless, no burning trees on the road edges or flying embers were reproduced in the scenario to not affect the driving trajectory and focus on the impact of smoke on driving. Each participant was driving on the same road. The road 


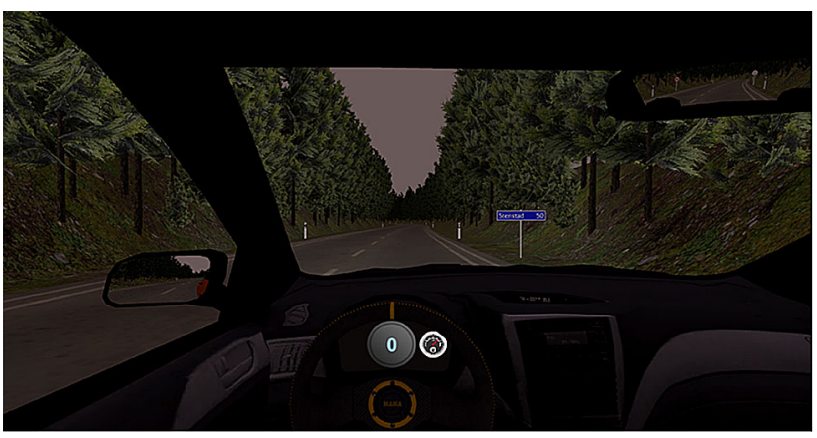

\section{Figure 2. Screenshot of driver view from the driver seat in the smoke-free condition. This includes the road and surrounding terrain.}

was created to be long enough to make it impossible to reach the other end before the experiment was completed.

The smoke was reproduced using the fog function in Unity. This function allows the user to specify the optical density per $\mathrm{m} D_{L}$ and get the desired amount and colour of the smoke (the colour RGB code in use is $105,89,89$, which was chosen to represent a colour which can resemble the smoke). This allowed to program changes of smoke density along the path. The sky was chosen to be in the same colour as the smoke in all driving conditions, even when there was no smoke on the road, in order to reproduce the conditions experienced in a wildfire scenario. This had no impact on the visibility from the driver seat and was just for visualisation purposes. Different smoke conditions were chosen in order to be representative of different visibility levels, namely No Smoke, Low (optical density per $\mathrm{m} D_{L}=0.05 \mathrm{~m}^{-1}$ ), Medium (optical density per $\mathrm{m} D_{L}=0.10 \mathrm{~m}^{-1}$ ), High (optical density per $\mathrm{m} D_{L}=0.15 \mathrm{~m}^{-1}$ ), and Very High (optical density per $\mathrm{m}$ $\left.D_{L}=0.20 \mathrm{~m}^{-1}\right)$. The selection of the visibility in the experiments was made to resemble possible conditions in a wildfire evacuation. The chosen interval was selected as a very high visibility would likely not affect driving, while a very poor visibility (i.e. close to 0) may discourage evacuees from continuing driving. Figure 2 shows the driver view from the seat in smoke-free conditions. Figure 3 shows the view at the reproduced conditions with smoke.

The optical density per metre $D_{L}$ can be translated into visibility of reflecting objects (the objects ahead being illuminated by the car headlights), using Eq. 1.

$$
\text { Visibility }=\frac{\ln 10}{D_{L}}
$$

During the development of the VR environment, visual testing was also performed to confirm that the visibility of the objects ahead corresponded to the calculations. 

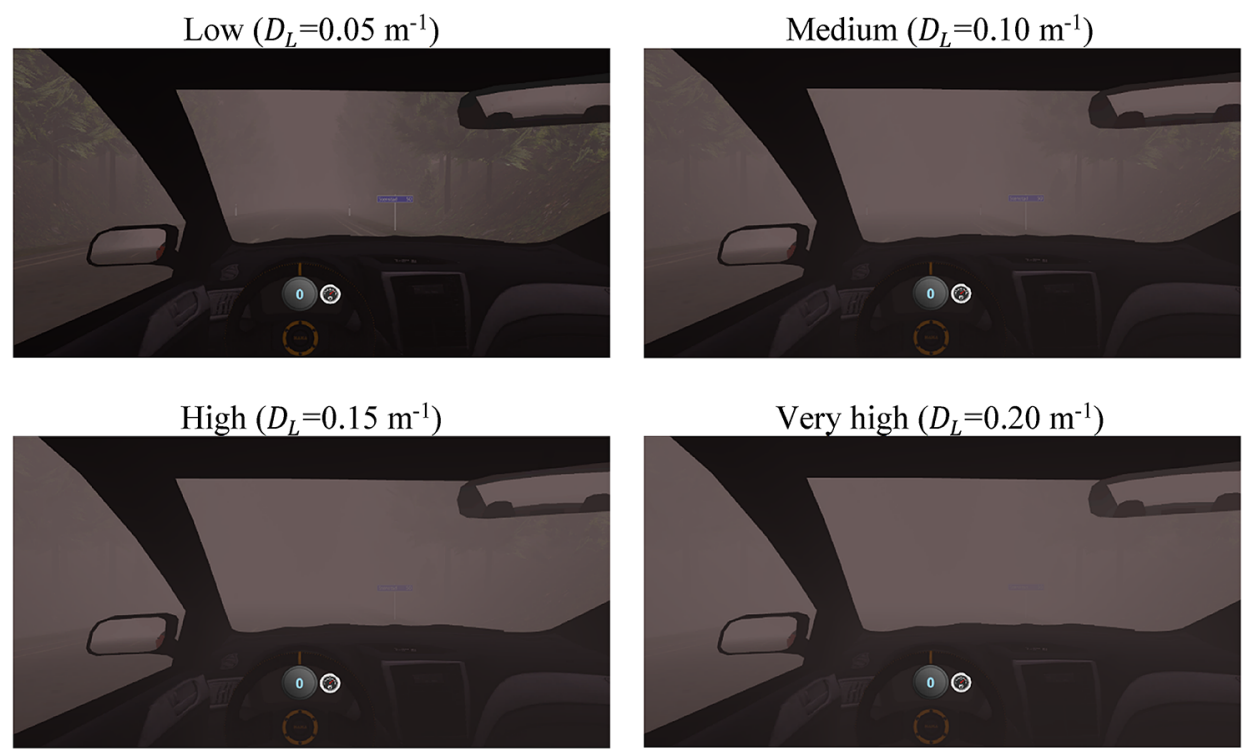

\section{Figure 3. Screenshot of driver view from the car seat in the low (top- left), medium (top-right), high (bottom-left) and very high (bottom- right) optical density conditions. This view includes the road and surrounding terrain.}

\subsection{The Wildfire Evacuation Scenario}

First, the participants were given the opportunity to get familiar with the driving task in VR in a smoke-free environment. The actual experiment then consisted of nine parts including five different visibility conditions. In the first part of the experiment, the driving conditions were the same as when the participant was trying the driving equipment (i.e. no smoke was present). After the test person had been driving for four minutes, smoke density will change in each consecutive sections (from low to very high $D_{L}$ and viceversa) until the participants were back at the condition of no smoke on the road. The smoke conditions corresponded respectively to visibility of approximately $11.5 \mathrm{~m}$ (very high smoke), 15 (high smoke), 23 (medium smoke) and $46 \mathrm{~m}$ (low smoke). The increase and decrease of smoke densities over the consecutive sections was made to investigate if entering thicker or thinner smoke would impact the choice of speed (i.e. if driving speed was influenced by the smoke density in the previously driven road segment).

To elicit a more realistic behaviour among the participants, force feedback in the steering wheel was used. Force feedback was included in the experiments by having the steering wheel slightly rotate back to the centre position, and by shaking. When the car was driven on the road, the steering wheel had a slight shake to simulate the roughness of the reproduced asphalt road. If the car got off the road and onto the nearby terrain, the steering wheel started to shake more to simulate driving on a bumpy road. Those effects were programmed to be dependent on the speed of the car and become stronger as the speed increases. 


\subsection{Procedure}

Recruitment information referred to an experiment on "people behaviour, perception and experience of realistic scenarios in VR". Inclusion (owning a valid driving license, being aged $18+$ ) and exclusion (cognitive or physical disabilities impeding driving, and other medical conditions such as epilepsy) criteria were also reported. The experiment took place at the laboratory of the fire safety engineering division at Lund University and it was performed during autumn 2019. Upon arrival, the participant was informed about the scenario and given an informed consent form to sign. The participants were told that they were going to experience a wildfire evacuation scenario and they had to evacuate by car. They were also told to behave as they would do in a real-life scenario. The participant was then seated and equipped with the VR-headset. In the first part of the experiment, the participant was given the opportunity to have a test drive to learn how the controls work and how the car behaves. This was generally lasting approximately $3 \mathrm{~min}$. When the participant was ready for the actual experiment, they were informed that they could terminate the experiment at any time and framed with the scenario:

During a severe drought during the summer, Sweden has started suffering from several large wildfires. Although the firefighters are working day and night to put out the fires, many of these fires are still spreading. Some of these fires are spreading towards areas where humans are at and if no further action is taken several lives will be at stake. Knowing this, a Swedish public authority has decided that mandatory evacuations are necessary. As you are currently in an area which soon will be threatened by one of the wildfires, you are informed that you must leave now in order to get away from it. You are therefore instructed to get to a location which currently is not at risk of getting involved with the fire. The road you are on is the road to the safe location and you are supposed to continue on this road until you get there.

After the participant had completed the experiment, they were asked to fill out a survey with questions on the experiments and background questions. The questions involved the use of a Likert Scale (a 7-point scale from -3 to +3 ). The options corresponding to -3 and +3 were accompanied by a text, see:

How afraid were you of getting into an accident during the simulation?

$[-3=$ not afraid at all, $-2,-1,0,+1,+2,+3=$ very afraid $]$

How urgent did you perceive the evacuation?

$[-3=$ not urgent at all, $-2,-1,0,+1,+2,+3=$ very urgent $]$

How high risk of the wildfire did you perceive?

$[-3=$ no risk at all, $-2,-1,0,+1,+2,+3=$ very high risk $]$

How realistic was the risk of harm from the wildfire?

$[-3=$ very unrealistic, $-2,-1,0,+1,+2,+3=$ very realistic $]$

How realistic was the handling of the car?

$[-3=$ very unrealistic, $-2,-1,0,+1,+2,+3=$ very realistic $]$

How realistic was the visual environment? 


$$
[-3=\text { very unrealistic, }-2,-1,0,+1,+2,+3=\text { very realistic }]
$$

After the participant had completed the survey, they had the opportunity to ask questions about the experiment and provide comments. The participants were then thanked, and they left the experimental room.

\section{Results}

The parametric equations of the participants' driving trajectories, along with the instantaneous speeds were recorded during the experiments every $0.5 \mathrm{~s}$. Data from the first $45 \mathrm{~s}$ of each experiment was discarded as this time has been estimated as the maximum time needed by participants to accelerate and reach their desired speed. In addition, qualitative information on the overall driving experience were collected through the questionnaire.

Data points of instantaneous speeds of the 46 participants under the different visibility conditions were recorded during the experiments. A summary of how many driving minutes are recorded for each visibility level is given in Table 1 . It should be noted that a longer driving task was performed at the set values of optical density per $\mathrm{m}\left(0.05 \mathrm{~m}^{-1}, 0.1 \mathrm{~m}^{-1}, 0.15 \mathrm{~m}^{-1}, 0.2 \mathrm{~m}^{-1}\right)$ compared to a shorter duration of driving in the transition between different visibility levels (this is because people were driving for a longer time in set values of visibility).

The complete set of instantaneous speed data-points and a linear regression model are plotted in Fig. 4. The solid green line is the linear regression model (see Eq. $2, \mathrm{R}^{2}=0.5971$ ). This model has been chosen due to its simplicity of use for future implementation in traffic modelling tools. In addition, it was decided to not use polynomial models as they may give non-monotonic functions, thus providing models which do not reflect the actual behaviour of people (i.e. speeds may get higher with lower visibility).

$$
v=-281.73 D_{L}+72.372 .
$$

The regression model presented here can also be reported in terms of speed $v(\mathrm{~km} /$ h) versus visibility of lit objects $D(\mathrm{~m})$ (this can be obtained using Eq. 1). The resulting model is presented in Eq. 3.

$$
v=-281.73 \frac{\ln 10}{D}+72.372 .
$$

It should be noted that this model should be considered applicable in the visibility range under consideration and for positive speed values.

An alternative analysis of the data was also performed. This consisted in aggregating the datapoints corresponding to the instantaneous speeds of each individual driver and then calculating the individual average driving speed at each discrete visibility level (see Fig. 5). The resulting linear regression model from this approach of analysis is presented in Eq. $4\left(R^{2}=0.6131\right)$. 


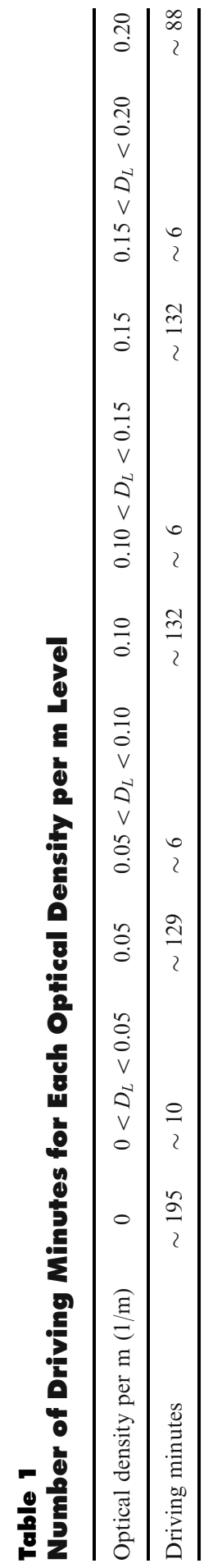




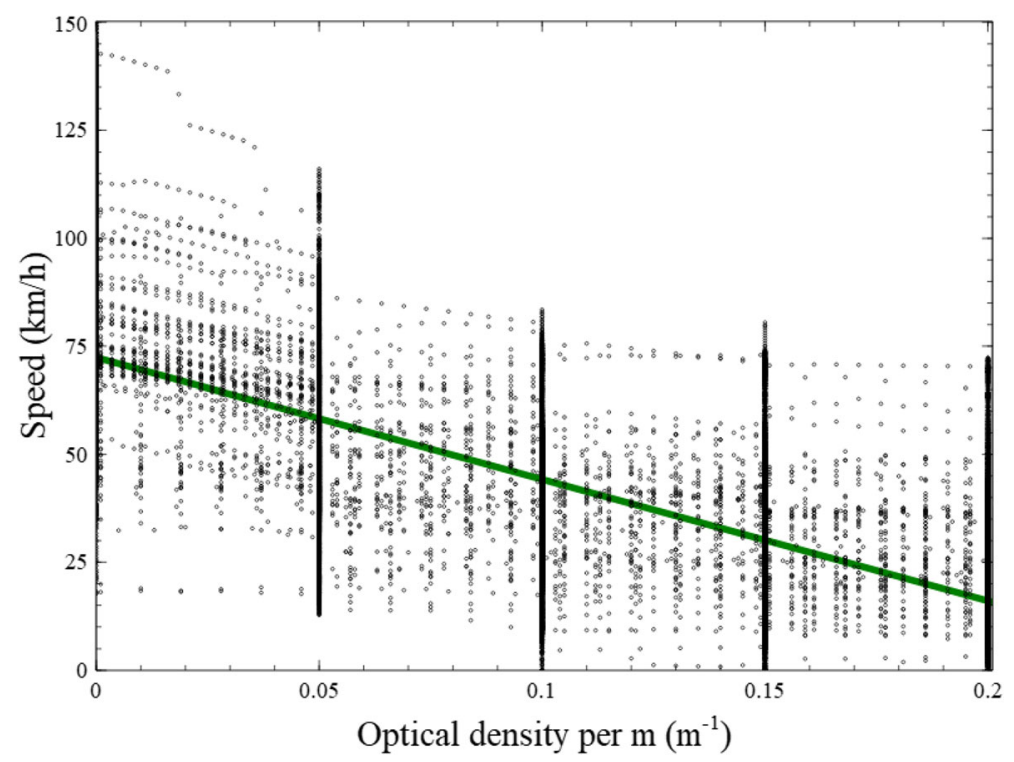

\section{Figure 4. Instantaneous speeds (in $\mathrm{km} / \mathrm{h}$ ) recorded during the experiments at different optical densities per $m\left(m^{-1}\right)$. The green solid line is a linear regression model based on the data.}

$$
v=-259.32 D_{L}+70.116
$$

This data aggregation was also used to investigate if statistical differences could be observed in the driving speeds of male (30 drivers) and female (15 drivers) at each visibility level. Kolmogorov-Smirnov tests were performed to test normality (each dataset corresponding to a given visibility level and was found to be normally distributed) and subsequently two-tailed t-tests were performed between the pairs (male vs female) of speed data-sets under a given visibility level. No statistical differences were found between the two groups.

As expected, there is large variation in the chosen speeds at all visibility levels. This is deemed to reflect the variability in driving speeds among people. Nevertheless, a clear trend of decreasing speeds with increasing smoke density can be observed.

An attempt to investigate if the visibility level (from thicker or thinner smoke) in the previously driven road segment has an impact on the overall chosen speed was performed. The data were split into two separate data series depending if the previous road segment had a higher or lower visibility level. Statistical testing (a non-parametric Kolmogorov-Smirnov test) was performed and it was not possible to prove any statistical difference between the two datasets. This seems to indicate that the choice of speed is rather influenced by the current visibility conditions rather than the speed driven at the previous road segment. 


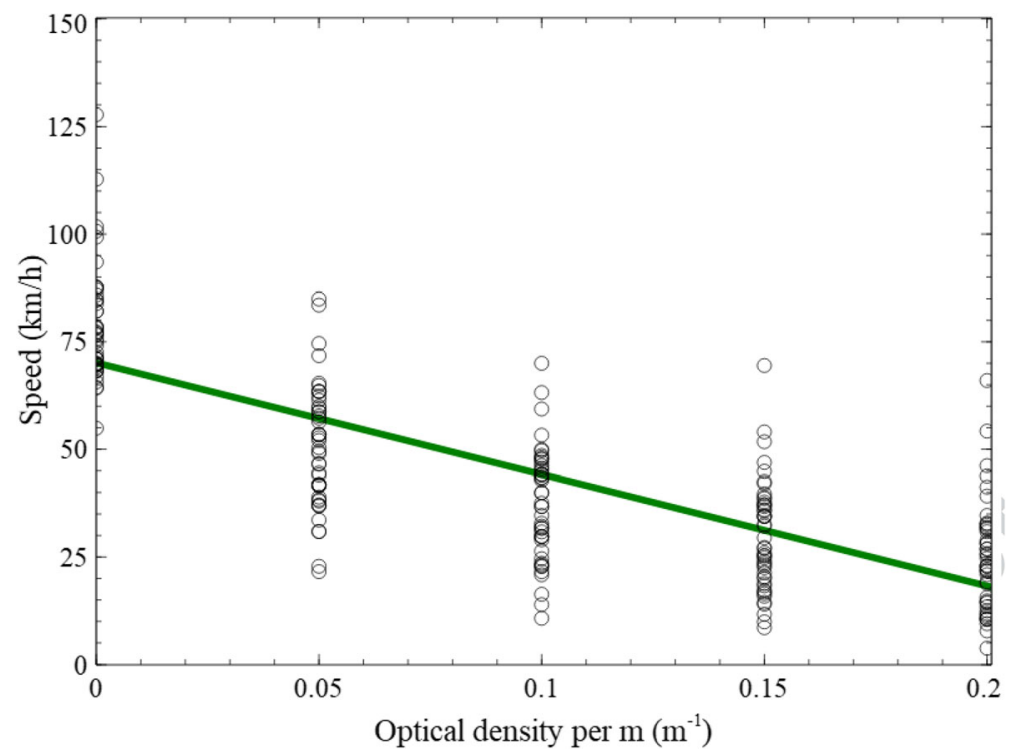

Figure 5. Aggregated average speeds (in $\mathrm{km} / \mathrm{h}$ ) recorded during the experiments at different optical densities per $m\left(m^{-1}\right)$. The green solid line is a linear regression model based on the data.

The choice of speed when driving through smoke can also be described as a fraction of the speed in clear conditions (this is the so called fractional speed $v_{f}$, a concept which is often used to describe walking speed in smoke $[1,12,17,31,33$, 38]). The fractional speeds are presented in Fig. 6 and a polynomial regression model is presented in Eq. 5 and it is valid for an interval between $\left[0 \mathrm{~m}^{-1}\right.$ and $0.2 \mathrm{~m}^{-1}$ ]. To facilitate its future implementation in traffic models, it should be noted that the best fit model has been modified in order to ensure that the intercept crosses the y axis at the value of 1 and that the model is a monotonic function.

$$
v_{f}=-101.57 D_{L}^{3}+49.43 D_{L}^{2}-9.2755 D_{L}+1 .
$$

Considering the 46 participants and the different visibility conditions, the instantaneous coordinates were obtained to study the centre location of the car during the driving test. This was used to study the distance the drivers kept to the centre line dividing the two lanes.

For each participant, the average distance to the centre line was then calculated for each smoke density. From these calculated values, the minimum, maximum, and average values as well as the standard deviation for each visibility level can be seen in Table 2. 


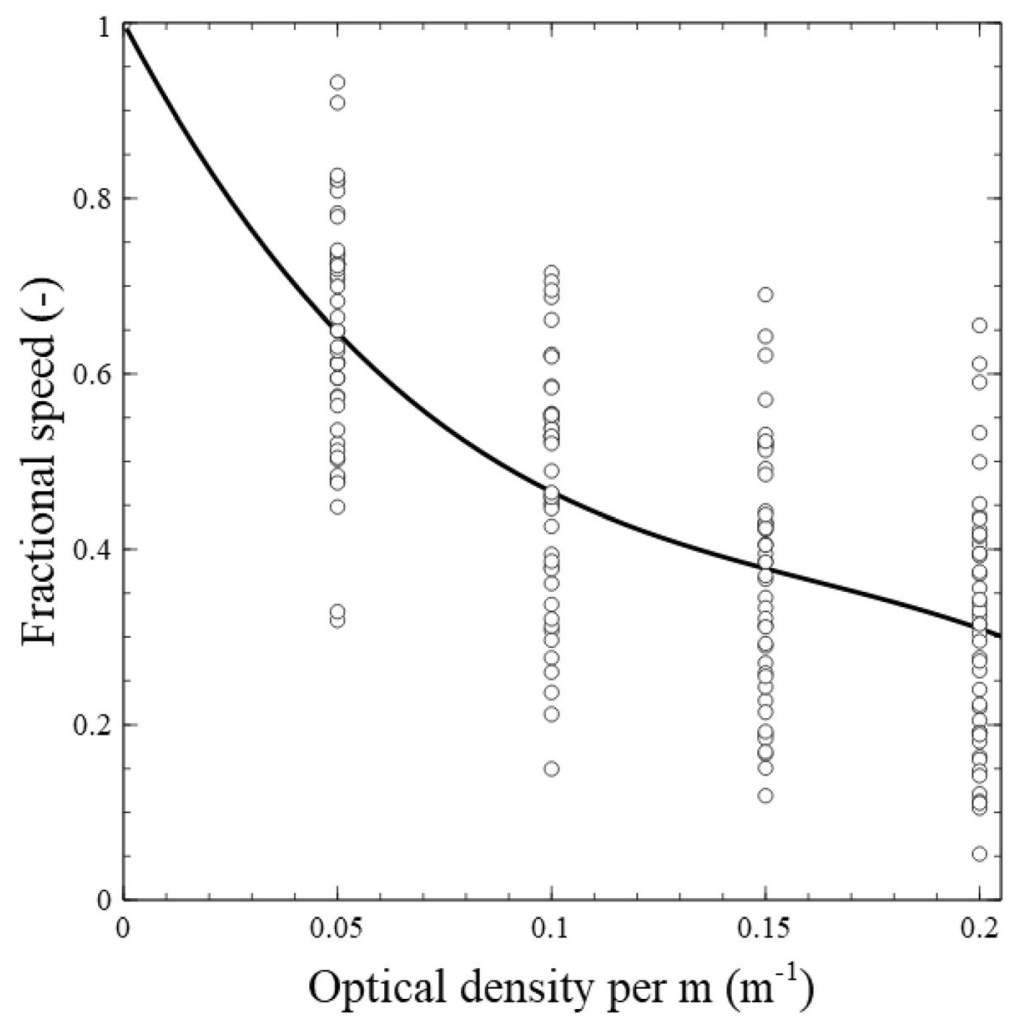

Figure 6. Fractional speed as a function of optical density per $m D_{L}$.

Statistical testing was performed (a normality test and then repeated t-tests) and no statistical difference was found in the car position in comparison the centre line between the smoke density levels.

The post-experiment questionnaire was administered to obtain qualitative observations on the experiments. The participants were asked to answer six questions regarding their experience and perceptions during the experiment. The results of these questions can be found in Fig. 7.

Most of the participants reported that they were afraid of getting into an accident during the driving task (including driving off road or hitting an obstacle, e.g. another vehicle or a tree). Most participants also reported a high level of urgency during the experiments, i.e., they felt a high risk from the wildfire scenario and an urgency to evacuate from the scenario. This question was intended to investigate both their perception during the simulation with the increasing smoke density, as well as their interpretation of the scenario based on the description received before the experiment started. The majority of participants also reported a high perceived wildfire threat. This question was - just as the question regarding the urgency of the evacuation - intended to be answered based on both the participant's interpretation of the scenario and their experiences during the simulation. Lastly, the par- 


\begin{tabular}{lccccc}
\hline & \multicolumn{5}{c}{ Smoke density level } \\
\cline { 2 - 6 } & No smoke & Low & Medium & High & Very high \\
\hline Distance & & & & & \\
Minimum & 0.98 & 1.11 & 1.10 & 0.73 & 0.33 \\
Average & 1.62 & 1.64 & 1.67 & 1.68 & 1.71 \\
Maximum & 1.94 & 2.12 & 2.10 & 2.09 & 2.20 \\
Standard deviation & 0.19 & 0.19 & 0.21 & 0.26 & 0.32 \\
\hline
\end{tabular}

ticipants were also asked about the realism of the experiment. Three different factors were considered regarding the realism of the experiment: the visual environment, the handling of the car, and the risk of harm from the wildfire. Figure 7 shows that most of the participants evaluated the realism positively or neutrally.

\section{Discussion}

To date, there is almost no research on how people drive in wildfire smoke. On one hand, this makes this study a necessary step for several wildfire safety stakeholders, e.g. traffic evacuation modellers and emergency responders. On the other hand, it is not possible to validate the results of the experiments with real world data.

The findings of this study clearly indicate that people tend to reduce their driving speed in smoke-filled environments. This is in line with research studies concerning walking speeds in smoke [31] and driving in fog [45] and it demonstrates that traffic models would need to implement this factor for their use in wildfire evacuation scenarios. This study indicates that the reduction of driving speed in wildfire smoke can get greater than in the presence of fog. In fact, the analysis of the fractional speeds show that the driving speed can get as low as to approximately $30 \%$ of the speed in clear conditions. This is a greater reduction than what reported in studies concerning driving in fog [45]. It is important to note that existing studies concerning driving speed in presence of fog are collected in normal conditions (i.e. not during an emergency), thus future comparisons should address this issue in light of the urgency of the situation.

No clear trend was found on the impact of the visibility conditions in the previously driven road segment. Traffic evacuation models currently neglect the impact of smoke and they do not explicitly consider the impact of reduced visibility conditions on speed [15]. They can subsequently produce non-conservative results when applied to wildfire evacuation scenarios.

Most of the participants reported being afraid of getting into an accident while driving in smoke. This is reasonable as the participants were experiencing high densities of smoke and had highly limited visibility. The scenario which the partic- 


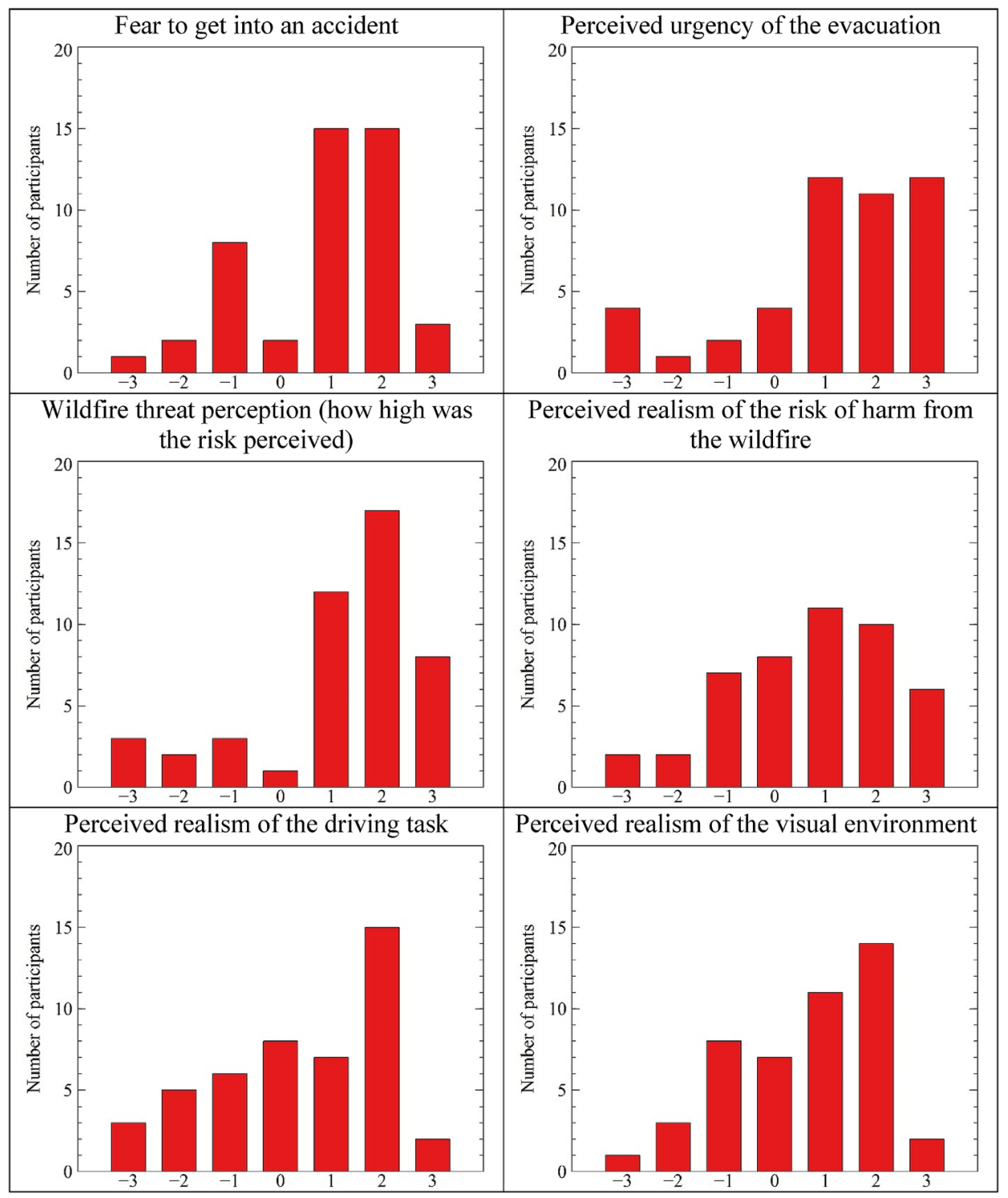

\section{Figure 7. Results of the participants' answers to the questions concerning their experience.}

ipants were facing was also a highly unfamiliar scenario as almost none of the participants had ever experienced a wildfire in real life. The combination of both limited visibility and an unfamiliar situation may provide an explanation on why they felt worried that they would get in an accident.

The perceived risk among the participants may be related to their limited experience on wildfires. As previously mentioned, only a few participants had any 
experience of wildfires. A speculation can be that a person who has previously experienced a wildfire would be less prone to wanting to pull over or turn around as $\mathrm{s} /$ he may not be aware of the negative consequences of driving through a wildfire. Alternatively, they may be more prone to drive faster as they have previously successfully evacuated an area affected by a wildfire. Another speculation could support the contrary: a person who has experienced a wildfire drives slower as $\mathrm{s} /$ he may have experienced issues with obstacles on the road and therefore drive more carefully than what was observed in the experiments. The impact of experience which leads to underestimate risks is linked to the anchoring bias, which is the tendency to rely on past (e.g., positive) experiences [20]. Similarly, risk underestimation can be linked to the cry wolf effect (a tendency to ignore a risk after experiencing situations with positive outcomes), which is a known issue in evacuation research [7, 10, 21, 22, 30, 42].

Some of the participants also mentioned - either in the survey or after the experiment was completed - that they felt stressed by the presence of smoke and the poor visibility. Feeling stressed during the experiment is in line with real wildfire evacuation situations [26] and it can then be seen as an indicator that the participants felt immersed by the environment, which enhances the validity of the results [19].

Other participants mentioned that they would have not driven as fast as they did if they had experienced the same scenario in real life. This issue may lead to an overestimation of the choice of speed among evacuees. Nevertheless, the average speeds in smoke-free conditions were in the order of $70 \mathrm{~km} / \mathrm{h}$ which is in line with what would be expected in the type of road under consideration. In modelling applications, this issue may lead to recommend the use of a fractional reduction of speed (see Eq. 5) based on the unimpeded speed in clear conditions of the road under consideration, as this provides a proportional reduction of speed rather than an absolute value for a given visibility condition.

Concerning the vehicle position on the road while driving in smoke, results do not show a clear relationship between the distance to the centre line on the road and smoke density. Nevertheless, it can be seen in Table 2 that the average distance to the centre line slightly increases as the optical density becomes higher. Although no statistical difference could be established, it is possible that drivers chose to drive further away from the centre when visibility is reduced. A possible explanation for this behaviour is that as the visibility is reduced, the drivers choose to go further to the right side of the road in order to have an extra margin to vehicles driving in the opposite direction (as the case study refers to a bi-directional road with right-hand traffic).

The result of the experiments is based on the trajectory data obtained from 46 people in 5 different visibility conditions and transitions between them. The participants were all students. A larger sample size with greater variations in their characteristics, such as occupation and experience as a driver, would allow a greater generalization of the findings. The average age among the participants was equal to 21.5 years old, thus the sample includes a young group of inexperienced drivers. This issue should be taken into consideration when using the results obtained, as younger drivers generally have a higher risk propensity [14]. An eval- 
uation of this issue was made comparing the impact of gender on observed driving speed, as young women are generally more risk averse in driving scenarios [25], but no statistical differences were found comparing the average speeds of the two groups under each visibility condition. In addition, young age can also have an impact on risk aversion in emergencies as younger men may be less likely to take protective actions [6]. These aspects should be taken into consideration while using the results obtained in this study.

Furthermore, the use of the results should consider the simplifications in the driving simulation setup and the surrounding environment. The driving setup included a gaming steering wheel which is smaller than an actual car steering wheel (as it is designed to resemble the steering wheel of a racing car). This limitation should be considered as the size of a steering wheel is known to have an impact on the driver (especially given existing steering wheel assistance systems which depends on steering wheel size [40]). Similarly, the driving seating position while performing the driving tasks did not correspond to an ordinary car. This might impact the posture of the driver while seating, which is known to have an impact on driving [29].

Regarding the virtual environment, there were no other vehicles on the road and no intersections. Although no information about whether or not there would be other vehicles on the road was given to the participants, participants may have assumed that - as there were no cars in the beginning of the experiment-there would not be any later on. Others may not have made this assumption. The lack of costs/consequences in VR may be linked to more risk-taking behaviour by participants during the experiments. Despite the simplifications in the scenario, no participant got off road and the observed speeds were reasonable given the type of road under consideration. It should also be noted that driving simulators have been tested in several contexts [44], with dedicated validation studies being performed for the performance of speed research [13]. This study confirms that driving simulators are able to elicit a sufficiently realistic driving behaviour for speed research. Assuming higher risk averse behaviour in the real world compared to VR may led to further advocating for the introduction of a reduction of driving speed due to the presence of smoke. The simplifications of the VR experiments should however be carefully considered when applying the results in real life situations.

The impact of reduced visibility due to wildfire smoke on driving has been investigated in isolation. Future research should focus on investigating the combination of reduced visibility with other variables which might affect a wildfire evacuation scenario from both an environmental perspective (e.g. different road layouts, signage, the presence of ember showers, different proximity levels of the wildfire threat, etc.) as well as the actual driving perspective (e.g. the behaviour of other drivers on the road, road management instructions, etc.).

\section{Conclusions}

This study shows that people tend to reduce their driving speed when the visibility is reduced due to wildfire smoke. There is a great variation in the speed at which the participants chose to drive. Simple regression models of driving speed versus 
visibility have been provided so that they could be implemented in traffic modelling tools. They consider either an absolute choice of speed based on the visibility conditions or a fractional choice of speed based on the individual speed in smoke-free conditions. No clear difference can be found regarding different choice of speed depending on the smoke density in the previously driven road segment. Despite the distance to the centre line does not clearly change based on the density of the smoke, a slight increase in distance has been observed as the smoke density increased.

\section{Acknowledgements}

Open access funding provided by Lund University.

\section{Compliance with Ethical Standards}

Ethical approval The Division of Fire Safety Engineering at Lund University has received approval from the Swedish ethical board to conduct Virtual Reality evacuation experiments under a given set of conditions and population.

Conflict of interest The authors declare that there is no conflict of interest regarding the publication of this article.

\section{Open Access}

This article is licensed under a Creative Commons Attribution 4.0 International License, which permits use, sharing, adaptation, distribution and reproduction in any medium or format, as long as you give appropriate credit to the original author(s) and the source, provide a link to the Creative Commons licence, and indicate if changes were made. The images or other third party material in this article are included in the article's Creative Commons licence, unless indicated otherwise in a credit line to the material. If material is not included in the article's Creative Commons licence and your intended use is not permitted by statutory regulation or exceeds the permitted use, you will need to obtain permission directly from the copyright holder. To view a copy of this licence, visit http://creat ivecommons.org/licenses/by/4.0/.

\section{References}

1. Akizuki Y, Yamao K, Tanaka T (2007) Experimental study on walking speed in escape route considering luminous condition, smoke density and evacuee's visual acuity. In: Seventh Asia-Oceania symposium on fire science and technology, Hong Kong, p 10

2. Albini FA (1983) Potential spotting distance from wind-driven surface fires. US Department of Agriculture, Forest Service, Intermountain Forest and Range Experiment Station 
3. Arias S, Wahlqvist J, Nilsson D, Ronchi E, Frantzich H (2020) Towards enhancing behavioural realism in virtual reality fire evacuation experiments. In: Interflam 2019: 15th International Conference and Exhibition on Fire Science and Engineering. London, UK

4. Baillie-de Byl P (2012) Holistic game development with unity: an all-in-one guide to implementing game mechanics, art, design, and programming. Focal Press, v

5. Blanchi R, Whittaker J, Haynes K, Leonard J, Opie K (2018) Surviving bushfire: the role of shelters and sheltering practices during the Black Saturday bushfires. Environ Sci Policy 81:86-94. https://doi.org/10.1016/j.envsci.2017.12.013

6. Bourque L, Russell L (1994) Experiences during and responses to the Loma Prieta earthquake. Governor's Office of Emergency Services, Sacramento, USA

7. Breznitz S (1984) Cry wolf: the psychology of false alarms. Lawrence Erlbaum Associates, Hillsdale

8. Brooks KR, Rafat ME (2015) Simulation of driving in low-visibility conditions: does stereopsis improve speed perception?. Perception 44:145-156

9. De Winter J, Van Leeuwen P, Happee R (2012) Advantages and disadvantages of driving simulators: a discussion. In: Proceedings of measuring behavior. Citeseer $\mathrm{p}$ 8th

10. Dow K, Cutter SL (1998) Crying wolf: repeat responses to hurricane evacuation orders. Coast Manag 26:237-252. https://doi.org/10.1080/08920759809362356

11. Folk LH, Kuligowski ED, Gwynne SM, Gales JA (2019) A provisional conceptual model of human behavior in response to wildland-urban interface fires. Fire Technol 55:1619-1647

12. Fridolf K, Ronchi E, Nilsson D, Frantzich H (2019) The representation of evacuation movement in smoke-filled underground transportation systems. Tunn Undergr Space Technol 90:28-41. https://doi.org/10.1016/j.tust.2019.04.016

13. Godley ST, Triggs TJ, Fildes BN (2002) Driving simulator validation for speed research. Accid Anal Prev 34:589-600

14. Hatfield J, Fernandes R (2009) The role of risk-propensity in the risky driving of younger drivers. Accid Anal Prev 41:25-35. https://doi.org/10.1016/j.aap.2008.08.023

15. Intini P, Ronchi E, Gwynne S, Pel A (2019) Traffic modeling for wildland-urban interface fire evacuation. J Transp Eng Part Syst 145:04019002

16. Jeon M, Walker BN, Yim J-B (2014) Effects of specific emotions on subjective judgment, driving performance, and perceived workload. Transp Res Part F Traffic Psychol Behav 24:197-209. https://doi.org/10.1016/j.trf.2014.04.003

17. Jin T (2008) Visibility and human behavior in fire smoke. In: SFPE handbook of fire protection engineering, 3rd ed. National Fire Protection Association, Quincy, MA (USA), pp 2-42-2-53

18. Jin T, Yamada T (1994) Experimental study on effect of escape guidance in fire smoke by travelling flashing of light sources. Fire Saf Sci 4:705-714. https://doi.org/10.3801/ IAFSS.FSS.4-705

19. Kinateder M, Ronchi E, Nilsson D, Kobes M, Müller M, Pauli P, Mühlberger A (2014) Virtual reality for fire evacuation research. In: 1st workshop "complex events and information modelling", Warsaw, pp 319-327

20. Kinsey MJ, Gwynne SMV, Kuligowski ED, Kinateder M (2018) Cognitive biases within decision making during fire evacuations. Fire Technol . https://doi.org/10.1007/ s10694-018-0708-0

21. LeClerc J, Joslyn S (2015) The cry wolf effect and weather-related decision making. Risk Anal 35:385-395. https://doi.org/10.1111/risa.12336 
22. Lim JR, Liu BF, Egnoto M (2019) Cry wolf effect? Evaluating the impact of false alarms on public responses to tornado alerts in the Southeastern United States. Weather Clim Soc 11:549-563. https://doi.org/10.1175/WCAS-D-18-0080.1

23. Lovreglio R, Kuligowski E, Gwynne S, Strahan K (2019) A modelling framework for householder decision-making for wildfire emergencies. Int J Disaster Risk Reduct 41:101274

24. McCaffrey S, Wilson R, Konar A (2018) Should I stay or should I go now? Or should I wait and see? Influences on wildfire evacuation decisions. Risk Anal 38:1390-1404

25. McGwin G Jr, Brown DB (1999) Characteristics of traffic crashes among young, middle-aged, and older drivers. Accid Anal Prev 31:181-198. https://doi.org/10.1016/S00014575(98)00061-X

26. McLennan J, Ryan B, Bearman C, Toh K (2019) Should we leave now? Behavioral factors in evacuation under wildfire threat. Fire Technol 55:487-516. https://doi.org/ 10.1007/s10694-018-0753-8

27. Mueller AS, Trick LM (2012) Driving in fog: the effects of driving experience and visibility on speed compensation and hazard avoidance. Accid Anal Prev 48:472-479

28. Pel AJ, Bliemer MCJ, Hoogendoorn SP (2012) A review on travel behaviour modelling in dynamic traffic simulation models for evacuations. Transportation 39:97-123. https:// doi.org/10.1007/s11116-011-9320-6

29. Porter JM, Gyi DE (1998) Exploring the optimum posture for driver comfort. Int J Veh Des 19:255-266

30. Rigos A, Mohlin E, Ronchi E (2019) The cry wolf effect in evacuation: a game-theoretic approach. Phys Stat Mech Its Appl 526:120890. https://doi.org/10.1016/ j.physa.2019.04.126

31. Ronchi E, Fridolf K, Frantzich H, Nilsson D, Walter AL, Modig H (2018) A tunnel evacuation experiment on movement speed and exit choice in smoke. Fire Saf J 97:126136. https://doi.org/10.1016/j.firesaf.2017.06.002

32. Ronchi E, Gwynne SM, Rein G, Intini P, Wadhwani R (2019) An open multi-physics framework for modelling wildland-urban interface fire evacuations. Saf Sci 118:868-880

33. Ronchi E, Gwynne SMV, Purser DA, Colonna P (2013) Representation of the impact of smoke on agent walking speeds in evacuation models. Fire Technol 49:411-431. https://doi.org/10.1007/s10694-012-0280-y

34. Ronchi E, Mayorga D, Lovreglio R, Wahlqvist J, Nilsson D (2019) Mobile-powered head-mounted displays versus cave automatic virtual environment experiments for evacuation research. Comput Animat Virtual Worlds . https://doi.org/10.1002/cav.1873

35. Ronchi E, Nilsson D (2018) Pedestrian movement in smoke: theory, data and modelling approaches. In: Gibelli L, Bellomo N (eds) Crowd dynamics, vol 1. Springer, Cham, pp 37-62. 10.1007/978-3-030-05129-7_3

36. Ronchi E, Rein G, Gwynne S, Wadhwani R, Intini P, Bergstedt A (2017) e-Sanctuary: Open multi-physics framework for modelling wildfire urban evacuation. Fire Protection Research Foundation, Quincy

37. Ruscio D, Bascetta L, Gabrielli A, Matteucci M, Ariansyah D, Bordegoni M, Caruso G, Mussone L (2017) Collection and comparison of driver/passenger physiologic and behavioural data in simulation and on-road driving. In: 2017 5th IEEE international conference on models and technologies for intelligent transportation systems (MT-ITS). IEEE, pp 403-408

38. Seike M, Kawabata N, Hasegawa M (2016) Experiments of evacuation speed in smokefilled tunnel. Tunn Undergr Space Technol 53:61-67. https://doi.org/10.1016/ j.tust.2016.01.003 
39. Snowden RJ, Stimpson N, Ruddle RA (1998) Speed perception fogs up as visibility drops. Nature 392:450

40. Tagesson K, Jacobson B, Laine L (2014) The influence of steering wheel size when tuning power assistance. Int $\mathbf{J}$ Heavy Veh Syst 21:295. https://doi.org/10.1504/ IJHVS.2014.068099

41. Tohidi A (2016) Experimental and numerical modeling of wildfire spread via fire spotting. Ph.D. thesis, Clemson University

42. Trainor JE, Nagele D, Philips B, Scott B (2015) Tornadoes, social science, and the false alarm effect. Weather Clim Soc 7:333-352. https://doi.org/10.1175/WCAS-D-14-00052.1

43. Westhaver A (2017) Why some homes survived: learning from the Fort McMurray wildland/urban interface fire disaster. Institute for Catastrophic Loss Reduction, Toronto

44. Wynne RA, Beanland V, Salmon PM (2019) Systematic review of driving simulator validation studies. Saf Sci 117:138-151. https://doi.org/10.1016/j.ssci.2019.04.004

45. Zhang W, Hu Z, Feng Z, Ma C, Wang K, Zhang X (2018) Investigating factors influencing drivers' speed selection behavior under reduced visibility conditions. Traffic Inj Prev 19:488-494

Publisher's Note Springer Nature remains neutral with regard to jurisdictional claims in published maps and institutional affiliations. 